\title{
Research on Online Self-Regulation of College Students in English Blended Learning
}

\author{
Yanghua Peng ${ }^{1, *}$ \\ ${ }^{1}$ School of International Studies, Chengdu College of Arts \& Sciences, Chengdu, Sichuan 610401, China \\ *Corresponding author. Email: pengls@126.com
}

\begin{abstract}
Recent researches have been conducted increasingly on learners' online learning at college with the background of the growing trend of educational informization. However, less attention has been paid to the relationship between self-regulation of English learning and the effectiveness of online learning. This study has carried out action research about the relationship between Chinese learners' online self-regulation and their effectiveness of online language learning by using questionnaires and surveys at a college in the southwest of China. Data were collected through the two questionnaires of the Effectiveness of Learning English (EOLE) and Online Self-regulated English Learning (OSEL). The research result shows that learners' environment structuring and goal setting could interpret their English language learning effectiveness in writing and further emphasizes the role of learners' self-evaluation, environment structuring and goal setting positively in the aspect of English language learning effectiveness.
\end{abstract}

Keywords: online self-regulation, effectiveness of online learning, correlation, blended language learning

\section{INTRODUCTION}

The outbreak of the COVID-19 makes online learning more popular than before. Individuals can enroll in self-study courses without the limitation of time and place. English language learning is not an exception. In English classes blended mode of teaching and learning and formative assessments are strongly recommended at many colleges. Accordingly, the online performances of English language learners become crucial for students' academic achievements increasingly. Many college students combine traditional learning with network, computers and even mobile devices to integrate these technologies into the learning process, so as to achieve a better learning effect and obtain higher learning effectiveness.

With the popularity of blended learning at colleges, it is claimed that online learning has stepped into college students' lives and became indispensable parts of their learning accordingly. There exists an essential distinction between the traditional classroom learning mainly based on the textbooks and teaching syllabus and the blended learning involved online and offline learning, in which online learning plays a particularly important role for their effectiveness in English language learning in terms of after-class learning and evaluation. Researchers at home and abroad have conducted a series of studies on explorations and practices of blended learning from different perspectives since it has many advantages over traditional learning with the development of the popularization of information technology. With the support of internet information technology, the issue of how to improve the learning effectiveness of blended learning has been the focus of researchers in various fields at home and abroad. However, literature reviews and visual analysis show us that few people focus on learners' self-regulation and its learning effectiveness in blended teaching and learning. This paper tries to find out the correlation between learners' self-regulation and learners' learning effectiveness at college English course.

\section{CENTRAL ISSUES}

\subsection{Blended learning}

Blended learning, as a new teaching method, has gradually been applied to college English teaching practice at home and abroad. In China, Professor He Kekang, director of the Institute of modern educational technology of Beijing Normal University, interprets blended learning as understanding the advantages of traditional learning methods and e-learning (i.e. digital learning or network learning) [1]. It combines the traditional face-to-face classroom instruction with E-learning and integrates the dual advantages of classroom learning and online leaming through the mutual complementation and promotion of both sides. Professor Li Jiahou, director of the Department of educational technology of Shanghai Normal University, believes that blended learning means integrated learning [2]. He focuses on the optimal combination of teaching media, teaching methods and teaching strategies. The application of online and offline teaching practice can enable to achieve the purpose of optimizing teaching and promoting learning. Professor Li Kedong, director of the Institute of modern educational technology of South China 
Normal University, believes that blended learning can be regarded as the integration of face-to-face instruction with online learning, which maximizes the benefits for students in the teaching process [3]. Foreign researcher Jennifer Hofmann (2001) holds that blended learning is a new idea. According to the characteristics of the teaching process, the instructor or scheme designer divides it into several stages, which optimizes the teaching in each stage, and finally realizes the learners' better understanding [4]. Michael Orey considers that blended learning should be defined from the perspectives of learners, teachers or instructional designers and teaching managers. According to his understanding, factors such as the learners' initial ability, the information literacy of teaching scheme designers and the real teaching environment should be considered in blended learning. Although these opinions seem to be different from each other to some extent, essentially they are similar in terms of trying to maximize the learning effectiveness. Researchers, teaching practitioners, the government and educational institutions have reached a consensus that blended teaching will become the main trend of future education especially in the context of the Internet plus.

\subsection{Self-regulation}

The concept of learners' self-regulation originates from the social cognitive learning theory represented by Albert Bandura in the 1970s and 1980s. In the late 1980s, Barry J. Zimmerman, American educational psychologist, tried to study learners' autonomous learning process and learning strategies from the perspective of learning psychology. In 1990, he put forward the concept of academic self-regulation. He thought that academic self-regulation was a multi-dimensional concept, which reflects the process of self-regulation from the aspect of cognition, metacognition, motivation, behaviour and environment in order to promote academic progress. Self-regulation is a multi-dimensional dynamic research concept, which integrates learners' learning strategy capacity, learning intent and learning behaviour, which not only reflects the level of learners' learning strategies, but also reflects the learners' intentional efforts and the ability to implement learning behaviours.

There are different explanations of learners' self-regulation in different theoretical schools, and social cognitive theory plays a great influence at present. From the perspective of social cognitive school, this study regards academic self-regulation of language learning as a dynamic and complex process in which second language learners maintain their cognitive, emotional and behavioural autonomy and development in order to achieve language learning goals.

It is claimed that self-regulation plays an important mediating role in learners' academic achievement. Online self-regulation of learners refers to a way of learning based on self-regulation in the network or online environment which is different from traditional self-regulation. According to Barnard, an American educational psychology researcher, online self-regulation is mainly composed of six elements (potential variables), namely goal setting, time management, environmental structuring, time management, help seeking strategy, task strategy and self-evaluation. These elements interrelate and interact with each other during the process of language learning. learners' online self-regulation should not be ignored for the success of language acquisition in blended learning. Therefore, self-regulation of learners in the network learning environment is considered to be an important factor in determining their academic learning effectiveness and personal development.

\subsection{Learning effectiveness}

Learning effectiveness refers to the degree to which learning results or outcomes have been achieved or that learning is effective. Under the principles of cognitive dimension, Gagne classifies learning results into five main categories: speech, wisdom, cognition, action and attitude. Different types of learning outcomes are caused by different behaviours of learners. In fact, in order to produce a good learning effect and obtain better learning results, different teaching conditions are required.

Data collected from CNKI shows that research on the learning effectiveness of blended learning is on the growing trend since 2015 . These researches are oriented to both cognitive perspective (learning ability, academic performance, etc.) and non-cognitive perspective (learning motivation, expectation, etc.) Some researchers focus on internal factors (learning motivation, self-efficacy, etc.) and external factors (learning resources, learning community, teachers' influence, etc.) that affect learners' learning effectiveness. There are also some focusing on learners' learning satisfaction degree, learning participation, learning cognition, learning tendency, learning emotional experience and so on. Still, some emphasize the organic mixing of various elements. The combination of micro-lectures, massive open online courses, small private online course and another traditional learning environment at colleges are expected to achieve high learning effectiveness. Obviously, learners with a low English language learning effectiveness profile performed rather differently from those with medium and high English language learning effectiveness profiles in terms of their use of self-regulated learning strategies. Presently college English language learners are empowered with various online applications or practices, so they can learn whatever they want to learn anywhere or anytime without the limitation of place and time. Thus technology-enhanced language learning practices enable English as foreign language students to engage in self-regulated learning and also exert a positive influence on their English language learning effectiveness as well. Students can be more confident while learning as they can obtain relevant material or information which is related to the course in web-based learning settings. Self-regulation of language learners is a crucial force affecting learning by surveying the samples of students who are exposed to an 
online learning environment sufficiently. This research focuses on answering the following two questions:

(1) What's the relationship between college students' online self-regulation and their English language learning effectiveness in blended learning?

(2) What role does college students' online self-regulation play in their English language learning effectiveness?

\section{RESEARCH METHOD}

\subsection{Context and Subjects}

This research was carried out at a college in Chengdu City, Sichuan Province, China in which English as a mandatory language course. In the research, the blended learning mode has been adopted in the course of college English to develop students' overall language competence. Teachers and students meet each other twice a week and there are sixteen weeks in a term. They can have a face-to-face instruction in classroom and interact online freely. Each class last for ninety minutes. Before class instructors require students to preview the online language learning materials related to the course and complete the self-regulated tasks assigned ahead of time on the online platform Ismart. It is convenient for both teachers and students to react to each other on the platform. The platform employed at many colleges is helpful for most of the students in assisting their online English learning.

Approximately 240 first-year undergraduate students enrolled at the college are the subjects involved in the research. All the participants had passed the college entrance examination conducted in China and completed formal English language learning for about six years in middle school. They also had online learning experience for sixteen weeks in accordance with the blended English language course at college. Data collected shows that more than half of the participants spend about 2 hours every week to learn English online after class.

\subsection{Instruments}

The research adopted the method of questionnaire and face-to-face inquiry to investigate the relationship between college students' online self-regulation and their English learning effectiveness in blended learning. The theories of self-regulation in educational psychology are employed to measure the college students' self-regulation ability and also monitor their English learning in online surroundings. The questionnaire is adapted from Barnard's article of measuring self-regulation in online and blended learning environments. In line with the previous instruments of Barnard's[5], the questionnaire on students' online self-regulation in this study was accordingly divided into six factors: goal setting (GS), environment structuring (ES), task strategies (TS), time management (TM), help seeking
(HS), and self-evaluation (SE). The questions involved the following six components.

(1) Goal setting: setting goals for time management in terms of online English learning

(2) Environment structuring: online sources available

(3) Task strategies: reading aloud online materials to avoid distractions

(4) Time management: online learning with fragmented time

(5) Help seeking: seeking help when meeting with problems online

(6) Self-evaluation: trying to find out how the performance is online by automatic scoring

The four language skills of listening, speaking, reading and writing, which are commonly mentioned, are measured in the second questionnaire.

(1) Listening: understanding simple conversations used daily such as asking for directions

(2) Speaking: talking about daily topics such as asking for help

(3) Reading: reading newspaper such as China Daily

(4) Writing: writing essays such as keeping diary without too many mistakes

\subsection{Data collection and analysis}

Before answering all these questionnaires, all participants in the investigation are told that they are free to choose any answer they like in the questionnaires and their responses will be kept secret. Invalid questionnaire data has been deleted; 200 students' responses have remained after deletion. Their answers would be analyzed after answering these research questions. Likert five grade scale is adopted in the two questionnaires of OSEL and EOLE, in which 5 points are the highest score indicating full agreement and 1 point indicating total disagreement [6]. The relationship between the OSEL and EOLE factors have been analysed by adopting the Pearson correlation analysis.

\section{RESULTS AND DISCUSSION}

The research result of the investigation is shown in the three tables. Table 1 shows the principal component analysis in the OSEL questionnaire from six factors. The results indicate that students approve of the environment structuring completely. Goal setting reflects learners' self-planning and self-requirements for English learning in the web-enhanced settings; environmental structuring reflects learners' ability to find a suitable learning environment for online learning; task strategy shows learners' ability to complete learning tasks by using various learning strategies in the process of online learning English; time management, help seeking and self-evaluation are explained learners' abilities to use time, seeking help from others, and self-reflection and evaluation in the process of online learning respectively. 
Table 1. Factors for the six factors of the OSEL

\begin{tabular}{|c|c|c|}
\hline Factor 1 & Goal setting & $\begin{array}{c}\alpha=0.90, \text { Mean }=3.64, \\
S D=0.75\end{array}$ \\
\hline Factor 2 & $\begin{array}{l}\text { Environment } \\
\text { structuring }\end{array}$ & $\begin{array}{c}\alpha=0.85, \text { Mean }=4.08, \\
S D=0.73\end{array}$ \\
\hline Factor 3 & Task strategies & $\begin{array}{c}\alpha=0.64, \text { Mean }=3.02 \\
S D=0.87\end{array}$ \\
\hline Factor 4 & $\begin{array}{c}\text { Time } \\
\text { management }\end{array}$ & $\begin{array}{c}\alpha=0.72, \text { Mean }=3.26 \\
\text { SD }=0.82\end{array}$ \\
\hline Factor 5 & Help seeking & $\begin{array}{c}\alpha=0.82, \text { Mean }=3.53 \\
\mathrm{SD}=0.84\end{array}$ \\
\hline Factor 6 & Self-evaluation & $\begin{array}{c}\alpha=0.83, \text { Mean }=3.33, \\
\text { SD }=0.82\end{array}$ \\
\hline
\end{tabular}

On the other hand, the principal component analysis of the EOLE questionnaire is shown in Table 2. The similar process is carried out in the survey.

Table 2. Factor and values for the four factors of the EOLE

\begin{tabular}{|l|l|l|}
\hline Factor 1 & Listening & $\alpha=0.87$, Mean $=3.18, \mathrm{SD}=0.61$ \\
\hline Factor 2 & Speaking & $\alpha=0.92$, Mean $=3.82, \mathrm{SD}=0.60$ \\
\hline Factor 3 & Reading & $\alpha=0.85$, Mean $=3.57, \mathrm{SD}=0.61$ \\
\hline Factor 4 & Writing & $\alpha=0.83$, Mean $=3.94, \mathrm{SD}=0.53$ \\
\hline
\end{tabular}

Furthermore, the correlation between the factors of OSEL and EOLE are obtained from the investigation. The survey adopted the Pearson correlation analysis to figure out the association between the learners' online self-regulation and their English language learning effectiveness. The correlation values can be seen among all the sub-scales in Table 3.

Table 3. Correlation between EFL students' OSEL and EOLE

\begin{tabular}{|l|l|l|l|l|}
\hline Factor & Listening & Speaking & Reading & Writing \\
\hline GS & $0.22 * * *$ & $0.28 * * *$ & $0.22 * * *$ & $0.37 * * *$ \\
\hline ES & $0.12 * * *$ & $0.22 * * *$ & $0.14 * * *$ & $0.27 * * *$ \\
\hline TS & $0.07 * * *$ & $0.15 * * *$ & $0.10^{* * *}$ & $0.14 * * *$ \\
\hline TM & $0.19 * * *$ & $0.21 * * *$ & $0.16^{* * *}$ & $0.24 * * *$ \\
\hline HS & $0.17 * * *$ & $0.23 * * *$ & $0.17 * * *$ & $0.25 * * *$ \\
\hline SE & $0.28 * * *$ & $0.32 * * *$ & $0.24 * * *$ & $0.31 * * *$ \\
\hline
\end{tabular}

Note. $* * * \mathrm{p}<.001$

All in all, the results of the findings indicate that the factors of OSEL make a crucial influence in predicting students' English effectiveness in blended learning. Meanwhile, environment structuring is the second important variable and goal-setting serves as a significant factor for the learners' effectiveness in English writing.

\section{CONCLUSION}

Though there are diversified ways of blending at colleges currently including the mixture of online and offline teaching processes, the mixture of different learning methods of students' autonomous learning and team learning, as well as the mixture of different evaluation methods. No matter what kind of mixing, the ultimate goal is to organically combine online learning and face-to-face learning so as to promote the optimization of teaching and improve students' learning effectiveness.

This research has adopted two questionnaires to figure out the relationship between college students' online self-regulation and their English language learning effectiveness in blended learning. The three tables show that the six factors i.e. goal setting, environment structuring, task strategies, time management, help seeking, and self-evaluation in students' online self-regulation and their English language learning effectiveness illustrated in the four language skills are interrelated mutually. Students with high online self-regulation are bound to perform better and get more satisfaction and achievements online. Accordingly, their language learning effectiveness will be superior to that of lower self-regulatory capacity and their productive skills of listening, speaking, reading and writing are also improved greatly. Also, goal setting and learning strategies as variables are significant for explaining the better performance which reflects language learning effectiveness during the process of online learning.

\section{ACKNOWLEDGMENT}

This study is strongly supported by the key research project of Chengdu College of Arts and Sciences (Grant WL 2020001).

The writing of the article is inseparable from the support of teachers and students of Chengdu College of Arts and Sciences. Their supports enable the author to complete the paper. Especially heartfelt thanks are expressed to Professor Wang Weimin, Mr. Yao Lianbing and Mrs. Zheng Chunping who give me guidance and warmth in my daily life. Their guidance, help and support have laid a solid foundation for my work and life. Their love and understanding have been the source of my writing. Finally, I'd like to thank my family and friends for their support and mutual supervision on the way of my life.

\section{REFERENCES}

[1] He Kekang, looking at the new development of educational technology theory from blending learning (I), Audio visual education in China, 2004.

[2] Li Jiahou. Definition and translation of blended learning [EB/OL].http: //www. jeast. net/jiahou/arehives/000618. html, 2008.

[3] Li Kedong, Zhao Jianhua. The principle and application mode of Blended Learning [J]. Audio visual education research, 2004. 
[4] Jennifer Hofmann. Blended Learning Case Study [EB/OL]. http://www.learning circuits.org/2001/apr20011hofmann, 2008.

[5] Barnard, L., Lan, W. Y., To, Y. M., Paton, V. O., \& Lai, S. L. Measuring self-regulation in online and blended learning environments. The Internet and Higher Education, 2009.
[6] Chunping Zheng, Jyh-Chong Liang, Yu-Fang Yang, Chin-Chung Tsai. The relationship between Chinese university students' conceptions of language learning and their online self-regulation, System, 2016. 